\title{
The Effective Injection Point of the Popliteal Region: A Cadaver Dissection Without Removing the Perineurium
}

\author{
Punto de Inyección Efectivo en la Región Poplítea: \\ Disección en Cadáver sin Remover el Perineuro
}

\author{
Youngjoo Sohn"; Young-Jin Lee**; Nam Seob Lee ${ }^{* * *}$; Seung Yun Han ${ }^{* * *}$; R. Shane Tubbs ${ }^{* * * *}$ \& Je-Hun Lee H** $^{* *}$
}

SOHN, Y.; LEE, Y. J.; LEE, N. S.; HAN, S. Y.; TUBBS, R. S. \& LEE, J. H. The effective injection point of the popliteal region: a cadaver dissection without removing the perineurium. Int. J. Morphol., 33(2):701-705, 2015.

SUMMARY: The aim of this study was to determine the in-depth anatomical location of the neurovascular structures important for nerve block. Forty fresh specimens from 22 adult Korean cadavers were used for this study. The average angle and depth of the bifurcation point of the sciatic nerve $(\mathrm{BC})$ was $18.7 \pm 3.6^{\circ}$ and $20.6 \pm 7.1 \mathrm{~mm}$, respectively. The point where the nerve branching point out for the muscles on the posterior compartment of leg were expressed in percentage distance relative to the vertical distance from popliteal crease to BC. The medial and lateral sural cutaneous nerve for $129.0 \%$ and $116.4 \%$, medial and lateral head of gastrocnemius for $137.2 \%$ and $141.9 \%$, the soleus for $179.5 \%$, the deep compartment of leg for $167.0 \%$. Our results provide detailed anatomical information to guide optimal nerve block.

KEY WORDS Popliteal block; Nerve block; Blind injection; Perineurium; Anatomical study.

\section{INTRODUCTION}

Popliteal nerve block (PopNB), often used during surgery to treat spasticity below the knee (Taboada Muñiz et al., 2003; Saleh et al., 2009), is considered relatively safe for providing an appropriate level of spinal anesthesia and reducing its possible side-effects. PopNB is reported to have excellent results regarding postoperative pain control (Jeon et al., 2013). However, side-effects in the popliteal region can occur in clinical practice (Compère et al., 2009). For blocking pain effectively, injections within the common connective tissue sheath have a higher success rate than injections outside the sheath (Lopez et al., 2014). Therefore, when considering nerve block, it is important for clinicians and researchers to understand the anatomical locations of the nerves (Driban et al., 2007).

In clinical practice, nerve block in the popliteal region is usually performed with ultrasound (US) guidance or nerve stimulation. However, nerve stimulation provides no benefit over ultrasound guidance alone when popliteal nerve block is attempted. US guidance alone has a significantly shorter block performance time (Robards et al., 2013). In addition, nerve block in the popliteal region involves a small or medium-sized field that surgeons sometimes inject blindly. Such injection does not take anatomical variations of the sciatic nerve (SN) into account. Therefore, incomplete block of the sciatic nerve in the popliteal fossa cannot be disregarded (Saleh et al.; Nader et al., 2009; Vloka et al., 2001). Accordingly, an anatomical study of the location of the $\mathrm{SN}$ in the popliteal fossa is required.

Anatomical studies focused on the popliteal region have been performed in various populations (Saleh et al.; Vloka et al.; Lee et al., 2013). Those studies have yielded different results regarding the location of the tibial nerve (TN) and common peroneal nerve (CPN) bifurcation in the popliteal fossa, but the depth and location of the nerves passing over the popliteal crease were not measured and it was unclear whether the perineurium was preserved during

* Department of Anatomy, College of Korean Medicine, KyungHee University, Seoul, South Korea

** Department of Rehabilitation medicine, Konyang hospital, Daejeon, Korea.

*** Department of Anatomy, College of Medicine, Konyang University of Korea, Daejeon, Korea.

***** Children's Hospital, Pediatric Neurosurgery, Birmingham, Alabama, United States of America.

This research was supported by basic science research program through the national research foundation of Korea (NRF) funded by the Ministry of Education, Science and Technology (NO. 2014R1A1A1006195). 
dissection. Of various methods used for PopNB, blocking the targeting nerve separately provides fast and effective results with patient satisfaction (Buys et al., 2010; Paqueron et al., 1999). The posterior approach is reported to be easy for supine positioning with short needle distance to reach the target structure (Khabiri et al., 2012). Accordingly, the present study investigated the location of nerves and vessels and depths from the skin from the posterior aspect. The aim was to determine in-depth the anatomical location of the neurovascular structures important for nerve block.

\section{MATERIAL AND METHOD}

Forty fresh specimens from 22 adult Korean cadavers (12 males and 10 females, age range 49-90 years, stature range $147-172 \mathrm{~cm}$ ) were used for this study. Cases with pathological changes or leg trauma were excluded.

The dissections were performed in the prone position with the lower limb extended. At this step, before dissection, the popliteal crease was identified and the vertical distance from the prominent point of the fibula head to the popliteal crease was measured. An incision was made on the posterior surface of the popliteal area. After the skin was removed, the superficial fascia was removed carefully to avoid damage to the perineurium so the nerves on the popliteal fossa could be identified (Figs. 1 and 2). The following variables were then measured: (1) the distance from the popliteal crease to the bifurcation point of the $\mathrm{SN}$; (2) the angle of the bifurcation point of SN; (3) the distance from the popliteal crease to the bifurcation point of the $\mathrm{SN}$; (4) the depth of the bifurcation point of the SN; (5) the distance from the bifurcation point to the branching point of the medial sural cutaneous nerve (MSCN); (6) the depth of the branching point of the MSCN; (7) the distance from the bifurcation point to the branching point of the lateral sural cutaneous nerve (LSCN); (8) the depth of the branching point of the LSCN (Figs. 1 and 3).

The present study also determined the direction in which the MSCN and LSCN branched out. Fat tissue was removed carefully to identify the branching point of the nerves that innervate the gastrocnemius, soleus, and deep compartment muscles of the leg. The following variables were measured: (1) the distance from the bifurcation point to the branching point to innervate the medial head of the gastrocnemius; (2)

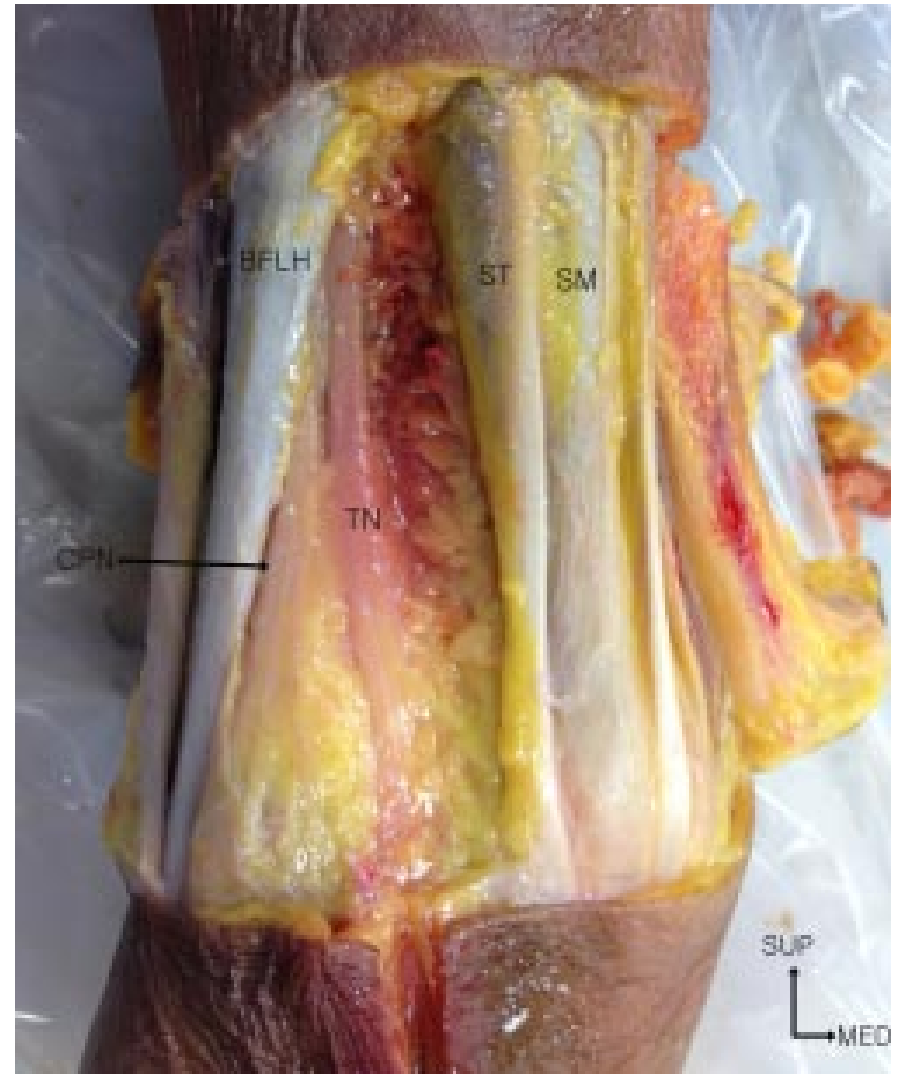

Fig. 1. The dissected sciatic nerve without removing the surrounding fat. $\mathrm{CPN}=$ common peroneal nerve; $\mathrm{TN}=$ tibial nerve; $\mathrm{BFLH}=$ long head of biceps femoris; $\mathrm{ST}=$ semitendinosus; $\mathrm{SM}=$ semimenbranosus; $\mathrm{SUP}=$ superior; $\mathrm{MED}=$ medial.

the depth of the branching point to innervate the medial head of the gastrocnemius; (3) the distance from the bifurcation point to the branching point to innervate the lateral head of the gastrocnemius; (4) the depth of the branching point to innervate the lateral head of the gastrocnemius; (5) the distance from the bifurcation point to the branching point to innervate the soleus; (6) the depth of the branching point to innervate the soleus; (7) the distance from the bifurcation point to the branching point to innervate the deep compartment muscles of the leg; (8) the depth of the branching point to innervate the deep compartment muscles of the leg. Therefore, a total of 17 variables were measured in this study. A few variables were also expressed in percentage distance relative to the vertical distance from popliteal crease to bifurcation point of sciatic nerve (Figs. 2 and 3).

A single observer made all the measurements using digitalized calipers (Absolute Digimetric; Mitutoyo Corp, Kanagawa, Japan) and a protractor (Songwha Corp, Yongin, Korea). Male and female cadavers were compared using Student's t-test. SPSS version 17.0 was used for all statistical analyses (SPSS Inc., Chicago, IL). Statistical significance was considered when $\mathrm{p}<0.05$. 


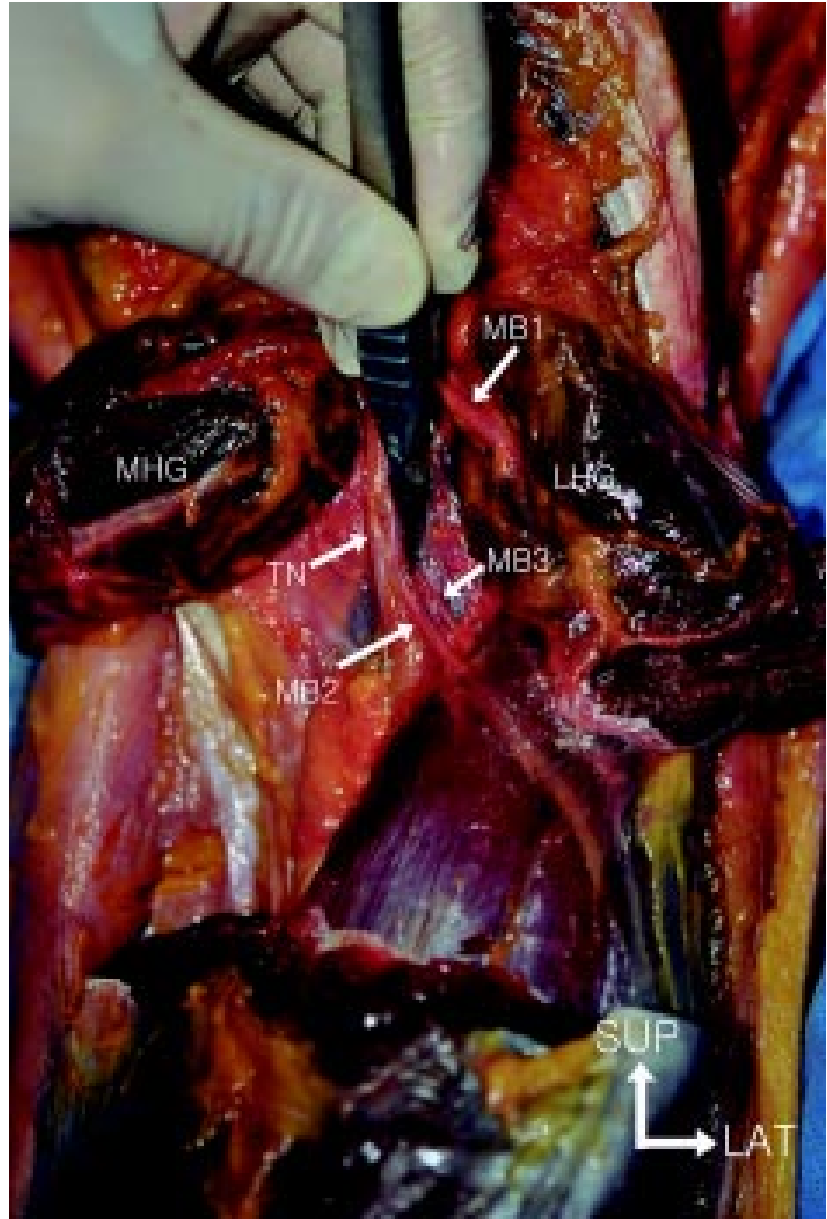

Fig. 2. The nerve branch to innervate the deep compartment muscles of the leg. $\mathrm{MHG}=$ medial head of gastrocnemius; $\mathrm{LHG}=$ lateral head of gastrocnemius; MB1= muscular branch to innervate gastrocnemius; $\mathrm{MB} 2=$ muscular branch to innervate soleus; $\mathrm{MB} 3=$ muscular branch to innervate deep compartment of the leg; SUP= superior; LAT = lateral.

\section{RESULTS}

The average angle and depth of the bifurcation point of the $\mathrm{SN}$ were $18.7 \pm 3.6^{\circ}$ and $20.6 \pm 7.1 \mathrm{~mm}$, respectively. The vertical distance from the most proximal point of the fibula head to the popliteal crease was $25.8 \pm 7.6 \mathrm{~mm}$. The distance from the popliteal crease to the bifurcation point of the $\mathrm{SN}$ was $63.9 \pm 9.8 \mathrm{~mm}$. There was no significant difference between males and females ( $\mathrm{P} \geq 0.05$ ) (Fig. 3).

The distance from the bifurcation point to the branching point of the MSCN was $83.0 \pm 15.1 \mathrm{~mm}$. The depth of the branching point of the MSCN was $11.0 \pm 4.8 \mathrm{~mm}$. The distance from the bifurcation point to the branching point of the LSCN was $74.4 \pm 21.2 \mathrm{~mm}$. The depth of the branching point of the LSCN was $9.8 \pm 3.2 \mathrm{~mm}$ (Fig. 3).

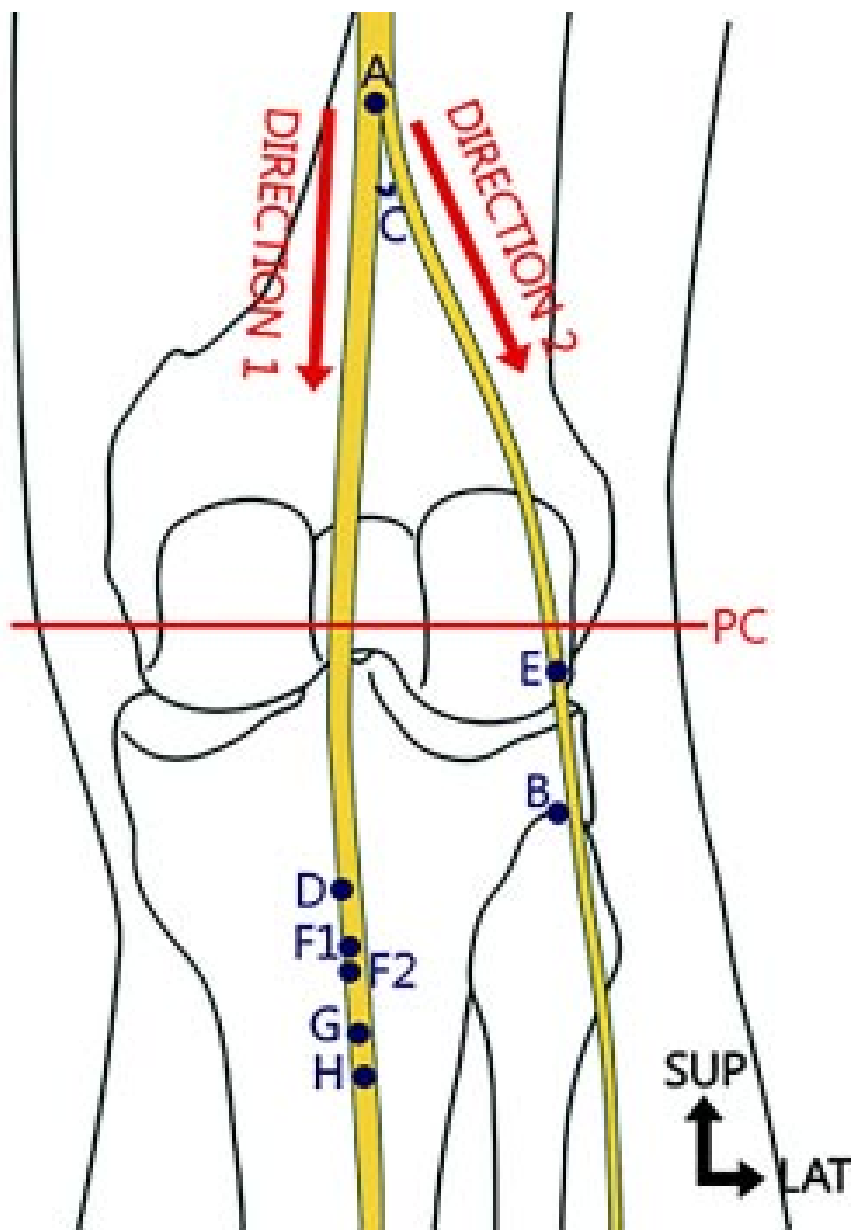

Fig. 3. The metric methods and results. The D, F1, F2, G, H, E variables were also expressed in percentage distance relative to the vertical distance from $\mathrm{PC}$ to $\mathrm{A}$. $\mathrm{PC}$ : popliteal crease, $\mathrm{A}=$ bifurcation point, $\mathrm{B}=$ the most proximal point of the fibula, $\mathrm{C}=$ the angle of the bifurcation point of sciatic nerve $\left(18.7 \pm 3.6^{\circ}\right), \mathrm{D}=$ branching point of medial sural cutaneous nerve, $\mathrm{E}=$ branching point of lateral sural cutaneous nerve, F1= branching point of medial head of gastrocnemius, $\mathrm{F} 2=$ branching point of lateral head of gastrocnemius, $\mathrm{G}=$ branching point to innervate the deep compartment muscles of the leg, $\mathrm{H}=$ branching point to innervate the soleus. According to direction 1 , distance $\mathrm{PC}$ and $\mathrm{A}=63.9 \pm 9.8 \mathrm{~mm}$, distance $\mathrm{A}$ and $\mathrm{D}=$ $83.0 \pm 15.1 \mathrm{~mm}(129.0 \%)$, distance, distance $\mathrm{A}$ and $\mathrm{F} 1=87.7 \pm 16.0$ $\mathrm{mm}(137.2 \%)$, distance $\mathrm{A}$ and $\mathrm{F} 2=90.7 \pm 16.5 \mathrm{~mm}(141.9 \%)$, distance $\mathrm{A}$ and $\mathrm{G}=106.7 \pm 15.7 \mathrm{~mm}(167.0 \%)$, distance $\mathrm{A}$ and $\mathrm{H}=114.7 \pm 14.0$ $\mathrm{mm}(179.5 \%)$. According to direction 2, distance $\mathrm{A}$ and $\mathrm{E}=74.4 \pm 21.2$ $\mathrm{mm}$. Vertical distance $\mathrm{PC}$ and $\mathrm{B}=25.8 \pm 7.6 \mathrm{~mm}$.

The distance from the bifurcation point to the branching point to innervate the medial head of the gastrocnemius was $87.7 \pm 16.0 \mathrm{~mm}$. The depth of the branching point to innervate the medial head of the gastrocnemius was $16.0 \pm 3.1 \mathrm{~mm}$. The distance from the bifurcation point to the branching point to innervate the lateral head of the gastrocnemius was $90.7 \pm 16.5 \mathrm{~mm}$. The 
depth of the branching point to innervate the lateral head of the gastrocnemius was $16.2 \pm 3.5 \mathrm{~mm}$ (Fig. 3).

The distance from the bifurcation point to the branching point to innervate the soleus was $114.7 \pm 14.0 \mathrm{~mm}$. The depth of the branching point to innervate the soleus was $18.0 \pm 4.5 \mathrm{~mm}$. The distance from the bifurcation point to the branching point to innervate the deep compartment muscles of the leg was $106.7 \pm 15.7 \mathrm{~mm}$. The depth of the branching point to innervate the deep compartment muscles of the leg was $21.0 \pm 4.1 \mathrm{~mm}$ (Fig. 3).

\section{DISCUSSION}

Previous cadaver dissection studies have reported that the SN bifurcates at various distances from the popliteal crease (Saleh et al.; Vloka et al.; Lee et al.). Vloka et al. reported that the SN divides a mean distance of $6.1 \pm 2.7 \mathrm{~cm}$ above the popliteal crease, with distances ranging from 0 to $11.5 \mathrm{~cm}$. Others have reported that it divides at $8.1 \mathrm{~cm}$ (range 5.0-18.0 $\mathrm{cm}$ ) from the popliteal crease (Saleh et al.). Other studies using Korean samples reported a distance of $7.9 \pm 2.6 \mathrm{~cm}$ (min: 4.0 $\mathrm{cm}$, max: $12.0 \mathrm{~cm}$ ) (Lee et al.). In the present study, the distance from the popliteal crease to the bifurcation point of the SN was $63.9 \pm 9.8 \mathrm{~mm}(6.4 \pm 1.0 \mathrm{~cm})$. Those differences in the measured distance could be attributed to dissection methods. In this study, we performed the dissection without removing the perineurium, which could contribute to such differences.

Aktan Ikiz et al. (2005) reported that the LSCN and MSCN were absent in $16.7 \%$ and $6.7 \%$ of specimens, respectively. Mestdagh et al. (2001) found that the LSCN and the MSCN were absent in $19.0 \%$ and $2.7 \%$ of specimens, respectively. In another study on a Korean population (Lee $e t$ $a l$.), the LSCN was not absent in any case but one of the 50 specimens; it branched out in two specimens; and the MSCN was absent in one case. In the present study, all specimens had both LSCN and MSCN. Discrepancies regarding the presence and absence of the LSCN or MSCN could be attributable to the samples used or the number of samples investigated.

In clinical practice, PopNB is usually injected under ultrasound (US) guidance. Several studies have described the advantages of US imaging (McCartney et al., 2004; Robards et al., 2009; Sinha \& Chan, 2004). Bruyn \& Schmidt (2009) reported that US-guided injections produced significantly better clinical outcomes than blind injections. However, USguided injections require the coordination of both hands. The results of the present study were obtained using the same circumference as in a clinical setting by preserving the perineurium. They will provide helpful information for effective nerve block if surgeons have to perform blind injections.

Muscular spasticity in the lower limb is common in post-stroke patients as an associated issue. Spasticity in lower limbs is a condition that frequently complicates stroke. It not only interferes with lower extremity function and limits daily activities, but also causes musculoskeletal complications. Detailed knowledge is required for selective neurolysis, which must be made as near as possible to the extramuscular nerve branching in order to better select the nerve branches that supply the muscles involved in spasticity (Lepage et al., 2005). The nerve locations of the popliteal fossa are important for effective neurolysis.

PopNB is a useful block for pain relief of the distal leg, specifically the distal tibia and fibula, ankle, and foot. Clinically, in an emergency setting, the ability to block the popliteal region is a powerful tool. We only required one attempt to position the needle tip successfully close to the nerve. However, clinicians are sometimes confronted with blind injections. In such a situation, this anatomical study will facilitate localization of the nerve, therefore decreasing the risk of injury.

To improve the success rate of PopNB, injecting a larger volume of local anesthetic might increase the spread within the epineural sheath. The major determinant of the block is the volume. However, we did not perform experiments regarding the volume, which is a limitation of this study.

In summary, after measuring 40 fresh specimens from 22 adult Korean cadavers, we found the average bifurcated angle of the SN was $18.7 \pm 3.6^{\circ}$. The $\mathrm{SN}$, with a depth of $20.6 \pm 7.1 \mathrm{~mm}$ from the surface, was located $63.9 \pm 9.8 \mathrm{~mm}$ from the popliteal crease. The MSCN and LSCN branched out at $83.0 \pm 15.1 \mathrm{~mm}$ and $74.4 \pm 21.2 \mathrm{~mm}$, with depths of $11.0 \pm 4.8$ $\mathrm{mm}$ and $9.8 \pm 3.2 \mathrm{~mm}$, respectively. The nerve locations of the medial and the lateral gastrocnemius head were $87.7 \pm 16.0 \mathrm{~mm}$ and $90.7 \pm 16.5 \mathrm{~mm}$, with depths of $16.0 \pm 3.1 \mathrm{~mm}$ and $16.2 \pm 3.5$ $\mathrm{mm}$, respectively. The nerve location of the soleus was $114.7 \pm 14.0 \mathrm{~mm}$, with a depth of $18.0 \pm 4.5 \mathrm{~mm}$. The distance from the bifurcation point to the branching point to innervate the deep compartment muscles of the leg was $106.7 \pm 15.7 \mathrm{~mm}$. The depth of the branching point to innervate the deep compartment muscles of the leg was $21.0 \pm 4.1 \mathrm{~mm}$. This study preserved the perineurium during dissection, as required in clinical practice. Our results provide detailed anatomical information for guiding optimal nerve block (Fig. 3).

ACKNOWLEDGEMENT. We thanks for donated bo $^{\circ}$ )es to our medical school. 
SOHN, Y.; LEE, Y. J.; LEE, N. S.; HAN, S. Y.; TUBBS, R. S. \& LEE, J. H. Punto de inyección efectivo en la región poplítea: disección en cadáver sin remover el perineuro. Int. J. Morphol., 33(2):701-705, 2015.

RESUMEN: El objetivo fue determinar en profundidad la localización anatómica de las estructuras neurovasculares importantes para el bloqueo del nervio poplíteo. Se utilizaron cuarenta muestras de 22 cadáveres coreanos adultos frescos. El ángulo medio y la profundidad del sitio de bifurcación del nervio ciático (BC) fue $18,7 \pm 3,6^{\circ}$ y $20,6 \pm 7,1 \mathrm{~mm}$, respectivamente. El punto en el que se identifica la ramificación del nervio para los músculos del compartimento posterior de la pierna se expresó en porcentaje de distancia relativa a la distancia vertical desde el pliegue poplíteo a BC. La distancia relativa de los nervios cutáneos sural medial y lateral fue $129,0 \%$ y $116,4 \%$, respectivamente; de las cabezas medial y lateral del músculo gastrognemio fue $137,2 \%$ y 141,9\%, del músculo sóleo fue $179,5 \%$, y del compartimento profundo de la pierna fue $167,0 \%$. Nuestros resultados proporcionan información anatómica detallada para guiar en forma óptima el bloqueo del nervio.

PALABRAS CLAVE: Bloqueo poplíteo; Bloqueo nervioso; Inyección ciega; Perineuro; Estudio anatómico.

\section{REFERENCES}

Aktan Ikiz, Z. A.; Uçerler, H. \& Bilge, O. The anatomic features of the sural nerve with an emphasis on its clinical importance. Foot Ankle Int., 26(7):560-7, 2005.

Bruyn, G. A. \& Schmidt, W. A. How to perform ultrasound-guided injections. Best Pract. Res. Clin. Rheumatol., 23(2):269-79, 2009.

Buys, M. J.; Arndt, C. D.; Vagh, F.; Hoard, A. \& Gerstein, N. Ultrasoundguided sciatic nerve block in the popliteal fossa using a lateral approach: onset time comparing separate tibial and common peroneal nerve injections versus injecting proximal to the bifurcation. Anesth. Analg., 110(2):635-7, 2010.

Compère, V.; Rey, N.; Baert, O.; Ouennich, A.; Fourdrinier, V.; Roussignol, X.; Beccari, R. \& Dureuil, B. Major complications after 400 continuous popliteal sciatic nerve blocks for post-operative analgesia. Acta Anaesthesiol. Scand., 53(3):339-45, 2009.

Driban, J. B.; Swanik, C. B. \& Barbe, M. F. Anatomical evaluation of the tibial nerve within the popliteal fossa. Clin. Anat., 20(6):694-8, 2007.

Jeon, H. J.; Park, Y. C.; Lee, J. N. \& Bae, J. S. Popliteal sciatic nerve block versus spinal anesthesia in hallux valgus surgery. Korean $J$. Anesthesiol., 64(4):321-6, 2013.

Khabiri, B.; Hamilton, C.; Norton, J. \& Arbona, F. Ultrasound-guided supine posterior approach for popliteal sciatic nerve block. J. Clin. Anesth., 24(8):680, 2012.

Lee, J. H.; Lee, B. N.; Lee, M. Y.; An, X. \& Han, S. H. The significance of tibial and common peroneal nerves in nerve blocks. Surg. Radiol. Anat., 35(3):211-5, 2013.
Lepage, D.; Parratte, B.; Tatu, L.; Vuiller, F. \& Monnier, G. Extra- and intramuscular nerve supply of the muscles of the anterior antebrachial compartment: applications for selective neurotomy and for botulinum toxin injection. Surg. Radiol. Anat., 27(5):420-30, 2005.

Lopez, A. M.; Sala-Blanch, X.; Castillo, R. \& Hadzic, A. Ultrasound guided injection inside the common sheath of the sciatic nerve at division level has a higher success rate than an injection outside the sheath. Rev. Esp. Anestesiol. Reanim., 61(6):304-10, 2014.

McCartney, C. J.; Brauner, I. \& Chan, V. W. Ultrasound guidance for a lateral approach to the sciatic nerve in the popliteal fossa. Anesthesia, 59(10):1023-5, 2004.

Mestdagh, H.; Drizenko, A.; Maynou, C.; Demondion, X. \& Monier, R. Origin and make up of the human sural nerve. Surg. Radiol. Anat., 23(5):307-12, 2001.

Nader, A.; Kendall, M. C.; Candido, K. D.; Benzon, H. \& McCarthy, R. J. A randomized comparison of a modified intertendinous and classic posterior approach to popliteal sciatic nerve block. Anesth. Analg., 108(1):359-63, 2009.

Paqueron, X.; Bouaziz, H.; Macalou, D.; Labaille, T.; Merle, M.; Laxenaire, M. C. \& Benhamou, D. The lateral approach to the sciatic nerve at the popliteal fossa: one or two injections? Anesth. Analg., 89(5):1221-5, 1999.

Robards, C.; Hadzic, A.; Somasundaram, L.; Iwata, T.; Xu, D. \& SalaBlanch, X. Intraneural injection with low-current stimulation during popliteal sciatic nerve block. Anesth. Analg., 109(2):673-7, 2009.

Robards, C. B.; Porter, S. B.; Logvinov, I. \& Clendenen, S. R. Success of ultrasound guided popliteal sciatic nerve catheters is not influenced by nerve stimulation. Middle East J. Anesthesiol., 22(2):179-83, 2013.

Saleh, H. A.; El-fark, M. M. \& Abdel-Hamid, G. A. Anatomical variation of sciatic nerve division in the popliteal fossa and its implication in popliteal nerve blockade. Folia Morphol., 68(4):256-9, 2009.

Sinha, A. \& Chan, V. W. Ultrasound imaging for popliteal sciatic nerve block. Reg. Anesth. Pain Med., 29(2):130-4, 2004.

Taboada Muñiz, M.; Álvarez, J.; Cortés, J.; Rodriguez, J. \& Atanassoff, P. G. Lateral approach to the sciatic nerve block in the popliteal fossa: correlation between evoked motor response and sensory block. Reg. Anesth. Pain Med., 28(5):450-5, 2003.

Vloka, J. D.; Hadzic, A.; April, E. \& Thys, D. M. The division of the sciatic nerve in the popliteal fossa: anatomical implications for popliteal nerve blockade. Anesth. Analg., 92(1):215-7, 2001.

\section{Correspondence to: \\ Je-Hun Lee \\ Department of Anatomy \\ College of Medicine \\ Konyang University of Korea \\ Daejeon \\ KOREA}

Received: 15-11-2014

Accepted: 20-04-2015

Email: leejehun@konyang.ac.kr 